\title{
Commentary
}

\section{Disaster of housing care amenities versus COVID-19 in urbanized countries: medication of social science}

\author{
Anwar Ali ${ }^{1 *}$, Munir Ahmed ${ }^{2}$, Ahmed Bostani ${ }^{3}$, Qurat U. Ain ${ }^{4}$, Ayesha Saeed ${ }^{4}$ \\ ${ }^{1}$ Hunan Provincial Key Laboratory of Clinical Epidemiology, Xiangya School of Public Health, Central South \\ University, Changsha, Hunan, China \\ ${ }^{2}$ Department of Food Science and Engineering, Yangzhou University, Yangzhou, Jiangsu, China \\ ${ }^{3}$ School of Tourism and Hotel Management, Dongbei University of Finance and Economics, Dalian, Liaoning, China \\ ${ }^{4}$ Department of Biochemistry, Government College University, Faisalabad, Punjab, Pakistan
}

Received: 07 March 2021

Accepted: 13 April 2021

\section{*Correspondence:}

Anwar Ali,

E-mail: 206908003@csu.edu.cn

Copyright: (C) the author(s), publisher and licensee Medip Academy. This is an open-access article distributed under the terms of the Creative Commons Attribution Non-Commercial License, which permits unrestricted non-commercial use, distribution, and reproduction in any medium, provided the original work is properly cited.

\begin{abstract}
In the background of the COVID-19 epidemic, a big portion of developed nations have suffered an exceptionally high human death toll residing in nursing care homes. In order to further explain this process, public epidemiology contributes significantly, due to the biological influence of the pathogen on as a core feature of wellbeing, disadvantaged high-risk communities and to the position of treatment. The catastrophe of deaths associated with COVID-19 in care centers is largely attributed towards its iatrogenic distribution and exacerbated by societal factors. Present segregation and containment measures have struggled to illustrate their efficacy in mitigating these trends, along with the extended alienation of tenants from their companions, and are thus excessive. Reforms that value for both protection interests of all citizens and fundamental rights must be substituted. Now about the dubious feasibility, these initiatives carry substantial costs of chances, because as standard of health and life conditions of isolated inhabitants are adversely impacted. The COVID-19 issue, viewed in specific from the prism of pharmacy as a public study and social epidemiology, creates ability to correctly appreciate and radically strengthen system parameters.
\end{abstract}

Keywords: COVID-19, Developed countries, Public epidemiology, Home cares

\section{INTRODUCTION}

From upper Silesia when Rudolf Virchow was sent to the field, In 1848, to examine the typhoid epidemic, he went on like a young scientist, who was subsequently considered to be one of the Pathology and infectology founders. ${ }^{1} \mathrm{He}$ has returned as one of the members of Epidemiology and social hygiene and, afterward, the sentence was coined by his friend, Neumann, medicine is social science and politics is nothing more but largerscale medicine. ${ }^{2}$

How did the comment hit Virchow? He witnessed the plight of the weak, terribly, miserably, nourished community, living together nearly in big, non-hygienic families. He was Confident that for the horrific breakout, outsiders was not possible to be accused. The Jewish community or somehow the mist was created by an unidentified terrible smell. Virchow has been confident that the pathogenic agents was a germ, but during that time, it hasn't been identified. Nonetheless, the chief reason he assumed would cause the social scenario was the epidemic of typhus. This that, nonetheless, prohibit him from disregarding the finding of Ignaz Semmelweis. To be recognized as the "savior of mothers," The infectious agent of puerperal sepsis is not inside the body or because of the uterine body women's thrombosis, but instead an iatrogenic infection triggered by doctors, bearing germs on their hands and being transmitted through them, one category to the next. ${ }^{3}$ In Wuhan, 
China, an epidemic of a novel corona virus has been detected in December 2019. On 30 January, the world health organization declared a global health emergency and a worldwide pandemic on 11 March, when the epidemic hit Iran, Europe from south and west to north and east, and later triggered outbreaks in the United States, Russia, Australia and New Zealand, gradually impacting countries in the Middle and South America and also the African continent.

\section{COVID-19 AND SOCIOLOGICAL FACTORS}

COVID-19 (as excellently elaborated by Prasad et al), simultaneously revealed and intensified existing disparities and unfair nesses inside a nation at a worldwide platform, rendering numerous communities extremely sensitive to COVID-19 and its complications, including individuals living in poverty, lacking accommodation, lacking daily residence, without jobs or indigenous communities in care homes. ${ }^{4,5}$ The response of policymakers, researchers and specialists in several moderate nations, while varying in depth, adopted a similar pattern: it began with tracking the very first victims, trying to locate the 'patient zero' backwards, concentrating on private care, particularly critical care units (ICUs), shutting boarders, sealing the whole inhabitants though almost tightly and quickly and completely limiting individuals who live in care facilities and gradually in all bigger firms from their families. ${ }^{6,7}$ Increasing 'reserve potentials' in emergency rooms and protecting the lives of residential care facility inhabitants were just the prime causes provided for the tighter isolation. They have been immediately most disadvantaged in such rising COVID-19 infection countries. Extreme results due to weakness and chronic comorbidities, subjected to workforce shortfall situations, inadequate access to precautions, and minimal training of employees in infection control practices. ${ }^{8,9}$

At the early part of the outbreak of COVID-19, health officials, biologists and medical professionals nevertheless, the upper society was worriedly concentrated on the ICUs. Most hospitals in Europe have reported worldwide rapidly optimizing efforts to create, decreasing postponable treatments and being capable of responding appropriately, albeit challenging the public's health problems linked to COVID-19. A disaster of much higher importance was to be discovered in the previously neglected 'side level' so frequently unrecognized: the tragic death of occupants in care homes, who have been residing within complete isolation for few weeks. For about every moderate nation, this method is especially useful, no matter if the citizens live in either a residential care home, free or privately financed. ${ }^{10}$ In New Zealand, several of the nation's only with smoothest and easiest to lock down, domestic isolation via the development of 'family household bubbles' and is one of the smallest rates of infection There was no avoidance of unnecessary deaths in care homes capable. ${ }^{11}$ What happened? Is this a fact of nature that such a group appeared to die only because of their feebleness and comorbidity? And another of kin, substantial someone else or legal advisors are kept away in order to protect people living within residential care homes, the least such nations will do.

It is increasingly obvious that perhaps the 'care home zone' is not a secure haven, however on the opposite, regardless of shutdown circumstances, a location of markedly higher risk. ${ }^{12}$ Therefore, our concern has become a hypothetical one and the response is: no, it's really not and this knowledge is not fresh. ${ }^{8-13}$ We should have learned all this from Virchow, Semmelweis or James Carville's popular Bill Clinton political campaign song of the essential role of financial factors (Table 1). This is really the narrative of the COVID-19 disaster noticeable in several moderate nations in such times, stated via the prism of science as a sociology, emphasizing background of healthcare and public epidemiology: Now with COVID-19 disease outbreak, developed nations have constructed their reactions guided by natural science and epidemiology, centered on the acute climate, safety equipment and monitoring, and developing ethical standards for the anticipated 'challenging' treatment in private care of safe and effective services such as ventilation systems or extracorporeal membrane oxygenation (ECMO). ${ }^{14,15}$ Since COVID-19 can impact a person without even being (immediately) symptomatic, the disease can quickly transmitted through health professionals and inhabitants' encounters despite lockout circumstances. It became evident including in fully skilled, exemplary nursing facilities with high-risk employees involved, practically transforming care facilities to 'grounds zero' and involuntarily leading to the fatalities of patient people who could not afford private care and treatment or in a stable place. ${ }^{16}$ A terrific 'viral dying' is being observed in residential care homes each fall in several moderate nations, before even COVID-19. COVID-19 is far more lethal relative to the above, and we actually have no vaccines but only very small possible treatments.

As even the existing evidence thus rapidly reveals, age, inadequacy and comorbidities are major causes, however according to Virchow's social latest research, the social background of care homes and other cultural establishments 10 in several moderate nations adds enormously to the casualty count themselves, with a range from zero percent (Hong Kong) to up to 85 perceived. ${ }^{8-14,16}$ Canada with excess numbers of care home fatalities not completely based on the actual proportion of regional COVID-19 associated fatalities. ${ }^{10}$ Caregivers, managers, house cleaning workers and physicians working in 'care home bubbles' don't really feel bad and therefore cannot be made accountable. That is the underlying supervisory rationale of several care home sites that holds the danger of experiencing a system with high and deadly facilities. 
Table 1: Campaign song of the essential role of financial factors.

Campaign song of the essential role of financial factors

A contagious 'attacker' doesn't really exist solely in 'expats' or 'individuals' (cultural or religious communities, refugees, tourists,' they), bringing pathogens to any' within (countries, organizations, households, a 'we')

A cultural construct, a concept haven't ever able to interrupt a natural occurrence such as an infectious infection, is to demarcate boundaries by technological walls or identify 'in' and 'out' communities.

People are susceptible to pathogens in large families (or shelters) because of their social setting, so this is not outward, but internal causes that are definitive.

Infectious diseases, nosocomial or otherwise, are easily distributed in different healthcare institutions where persons at large risk work closely around each other.

Hospital and health workers make a major contribution to the transmission of the disease.

If employees are short staffed, poorly equipped, underfunded, sent to duty also with indications, further more being checked together with inhabitants are absolutely stupidity.

Even if it is due to depleted care and support resources or the maximization of corporate equity as financial assets of major private firms operating community nursing homes, it's also doesn't really matter.

Indiscriminately, visit exclusion policies were unsuccessful in combating this epidemic and adversely affected both overall health and standard of life. ${ }^{17,18}$ The existing data clearly shows that the exclusion steps were not successful in avoiding the dissemination of COVID19.

\section{SOCIAL EPIDEMIOLOGY}

Due to the deterioration of depression and mental disorde rs, for example, by restricting social connections and restricting access to health services required, like appointmen ts to medical doctors (GPs) and experts in hospice care, physiotherapists, posologists, and several others. Finally, because of the ongoing isolation from the disadvantaged, the collective mortality with the most disadvantaged whic $\mathrm{h}$ accompany the biological one. Second, general practitioners needs to be improved so that policymakers, GPs, supervisors and hospital staff can better prepare and adapt to the changing needs of individuals living in psychiatric hospitals. Secondly, both, it is important to find innovative and secure solutions that allow for Inhabitants to stay in touch with their family members legal agents, thereby protecting the standard of living necessary basic dignity, to protect them. In there is no sense, trusting the partners or those who are correctly told next.

It is more risky for parents as well as legal officials to GPs, paramedics or housecleaning workers this theory is backed by recent and indeed existing evidence from different aspects Epidemiology and background of epidemic diseases. ${ }^{18}$ Unlike employers, on a stressful day, families do not even have to take care of 20 hospital patients at once, but only accompany their first and only mom, dad, and infant or good friend Offer love to your mate, a feeling of connection and security, within total lockdown circumstances, and greatly exacerbating the demanding nursing job of the professional workers. In addition, care facilities require the right safety devices and preparation to be used on both workers and families. There is a need for an extra cautionary note: not all planning capacity was lost by care home tenant's capacities. A lot of people also have the potential. Hence, they should be interested in decisions about and on medical treatment risks taken or averted. Even if many inhabitants just want be treated at home, In the event of a drastic worsening of fitness, not many wish to forego existence therapy, many like to be moved to health care facilities and ICUs that can be handled by government advance treatment scheduling. ${ }^{19}$

Any people vary in weighing independence and protection and wishing to see kids or grandkids, as promised by democratic countries to all inhabitants who are still responsible for the society as well. Thus the, care home managers must do their utmost to provide realistic, innovative solutions, for example, In try to reduce risks to both workers and people,' threat bearing' and 'threat forestalling classes' are segregated. What might have been the more common lesson to be learned in nursing homes from this example, actually occurring in most moderate nations, labelled as a human crisis by the Canadian theorist Monique Lanoix? ${ }^{20}$ When main communal populations with marginalized people are all at risk of being 'grounds zero,' we should restore 'old' proposals of tiny societies with aged or handicapped people, supported inside residential neighbourhoods by professional, possibly the best health professionals, which may even prove economical in overall. It will definitely be even more compassionate and secure, so as close to $85 \%$ of COVID-19-related fatalities in moderate nations are care home inhabitants, excluding Hong Kong, the introduction of regular entire care home checking of workers and the general public and a quick, rapid patient quarantine, Which must be analyzed properly and about $34 \%$ of all fatalities are inhabitants living at residential societies. ${ }^{8,10}$ The very next disease outbreak may not be as lethal, even without extremely successful therapies or a vaccine at hand, if individuals gather in community institutions. ${ }^{8,4}$ At last, we should turn to Dr Virchow again, arguing for further social equality, as 'politics on a wider scale was nothing more than medicine.' For a greater analysis of the determinants leading to these 
disasters and for the creation of better interventions, social epidemiology and the past of bacterial infections are important. If a decent portion of the budget currently spent on essential biological scientific research and touch monitoring in moderate nations contributes to the development, financing and recruitment of the care homes environment and even to certain 'large households' across the globe. ${ }^{21}$ The foregoing initiatives may possibly become the turning point to help cope for the next epidemic of infectious agent and avoid needless death and misery for several individuals around the world in order to create good quality of life.

\section{CONCLUSION}

The deaths linked to COVID-19 in health care facilities are due to the drug's iatrogenic delivery and compounded by social causes. Present segregation and enclosure policies have failed to demonstrate their usefulness in reversing these patterns, together with the prolonged separation of residents from their companions, and are therefore excessive. We require that reforms that uphold both public interests and fundamental rights take precedence. Now about the doubtful viability, these measures bear significant costs of chances, because as quality of health and life standards of isolated inhabitants are adversely impacted. The COVID-19 question, viewed in specific from the prism of pharmacy as a public analysis and social epidemiology, creates capacity to correctly appreciate and dramatically improve device parameters.

\section{ACKNOWLEDGEMENTS}

Authors would like to thank Central South University for providing us free access to the journals and library.

Funding: No funding sources

Conflict of interest: None declared

Ethical approval: Not required

\section{REFERENCES}

1. Virchow R. Mittheilungen über die in oberschlesien herrschende typhus-epidemie (news about the typhoid epidemic in upper silesia. Berlin: De Gruyter; 1848.

2. Mackenbach JP. Politics is nothing but medicine at a larger scale: reflections on public health's biggest idea. J Epidemiol Community Health. 2009;63:1814.

3. Kadar N, Romero R, Papp Z. Ignaz Semmelweis: the "savior of mothers": On the 200th anniversary of his birth. Am J Obstet Gynecol. 2018;219:519-22.

4. Prasad V, Sri BS, Gaitonde R. Bridging a false dichotomy in the COVID-19 response: a public health approach to the 'lockdown' debate. BMJ Glob Health. 2020;5:e002909.

5. Kali E. Coronavirus and the social determinants of health. Available at: https://ncrc.org/ coronavirus- and- the- social- determinants- of- health/. Accessed on 30 December 2020.

6. Wilkinson D. ICU triage in an impending crisis: uncertainty, pre-emption and preparation. J Med Ethics. 2020;46:287-8.

7. Emanuel EJ, Persad G, Upshur R. Fair allocation of scarce medical resources in the time of Covid-19. N Engl J Med. 2020;382:2049-55.

8. Salcher-Konrad M, Jhass A, Naci H. Updated findings: living systematic review of emerging evidence on COVID-19 related mortality and spread of disease in long-term care, 2020. Available at: https://ltccovid. org/ 2020/ 06/ 30/ updated- findingsliving-systematicreview- of- emerging- evidence- oncovid- 19- related- mortality- andspread- of- diseasein-long-term- care/. Accessed on 30 December 2020.

9. Burki T. England and Wales see 20000 excess deaths in care homes. Lancet. 2020;395:1602.

10. Comas-Herrera A, Zalakaín J, Litwin C. Mortality associated with COVID19 outbreaks in care homes: early International evidence. Available at: https:// ltccovid.org/wp-content/uploads/2020/06/Mortality associated-with-COVID-21-May-1. Accessed on 30 December 2020.

11. Health staff working to deal with dementia care facility COVID-19 cluster. Available at: https://www.rnz.co.nz/news/national/413602/ healthstaff- working- to- deal- with- dementia- carefacilitycovid- 19- cluster. Accessed on 30 December 2020.

12. Koshkouei A, Abel L, Pilbeam C. How can pandemic spreads be contained in care homes? Available at: https://www.cebm.net/covid-19/howcan-pandemic-spreads-be-contained-in-care- homes/. Accessed on 30 December 2020.

13. Birnbaum M, Booth W. Nursing homes linked to up to half of coronavirus deaths in Europe, who says. Washington post, 2020. Available at: https://www. washingtonpost.com/world/europe/nursing homescoronavirus-deaths- europe/ 2020/ 04/ 23/ d635619c8561-11ea-81a3-9690c9881111_story.Html.

Accessed on 30 December 2020.

14. Etard J-F, Vanhems P, Atlani-Duault L. Potential lethal outbreak of coronavirus disease (COVID-19) among the elderly in retirement homes and long-term facilities, France, March 2020. Euro Surveill. 2020; 25:2000448.

15. Truog RD, Mitchell C, Daley GQ. The Toughest triage allocating ventilators in a pandemic. $\mathrm{N}$ Engl $\mathrm{J}$ Med. 2020;382:1973-5.

16. Barnett ML, Grabowski DC. Nursing homes are ground zero for covid-19 pandemic. JAMA Health Forum. 2020.

17. Gordon AL, Goodman C, Achterberg W. Commentary: COVID in care homes-challenges and dilemmas in healthcare delivery. Age Ageing. 2020;13:afaa113.

18. Abramson A. Protecting nursing home residents during COVID-19. American psychological association. Available at: http://www.apa.org/ 
topics/covid-19/nursing- home- residents. Accessed on 30 December 2020.

19. Brinkman-Stoppelenburg A, Rietjens JAC, van der Heide A. The effects of advance care planning on end-of- life care: a systematic review. Palliat Med. 2014;28:1000-25.

20. Lanoix M. Nursing homes in the time of Covid-19. impact ethics. Available at: https:// impactethics. ca/2020/04/21/nursing-homes- in- thetime- of- covid19. Accessed on 30 December 2020.
21. Oliver D. let's not forget care homes when covid-19 is over. BMJ. 2020;369:m1629.

Cite this article as: Ali A, Ahmed M, Bostani A, Ain QU, Saeed A. Disaster of housing care amenities versus COVID-19 in urbanized countries: medication of social science. Int J Sci Rep 2021;7(5):293-7. 